\title{
Observation Modeling for Continuous Predicting Global and Diffuse Solar Radiation on Horizontal Surface
}

\author{
${ }^{1}$ Somporn Hongkong and ${ }^{2}$ Singthong Pattanasethanon \\ ${ }^{1}$ Department of Mechanical Engineering, Faculty of Engineering, \\ ${ }^{2}$ Department of Electricaland Computer Engineering, Faculty of Engineering, \\ Mahasarakham University, Khantaravichai, Mahasarakham 44150, Thailand
}

Received 2013-01-07, Revised 2013-01-20; Accepted 2013-05-23

\begin{abstract}
Mathematical modeling for continuous prediction of solar energy is inevitable for energy systems. General, existing models are mostly empirical and data dependent. This article has to present a variable model for predicting global and diffuse solar radiation on the horizontal plane. The model considered in this study has applied Hidden Markov Model (HMM) with two observations. The databases were measured according CIE standard since 2004 to 2010 for model synthetics. The new data of 2011 year used for testing model. Training, take data in time sequence and clustering. After that, create transition probability in each state have two observations matrix; Sky Ratio (SR) and solar altitude angle $(\alpha)$ are observation value of the model. Predicting, values of solar radiation are considered as the hidden events by will been calculate probability of observation from $\mathrm{P}$ [SR $\cap \alpha$ ], state as highest probability was selected for predict state and convert to solar radiation quantity. Model evaluation, three statistical namely MBD, RMSD and R2were used for model evaluations. The results show that, this model is appropriate for predicting sky quantities. Conclusion, the variable model from the synthesis was suitable for predicting long-term data with observation value. The advantage of this study showed that we could predict sky the quantity value when we only knew the observation values.
\end{abstract}

Keywords: Sky Model, Observation Model, Hidden Markov Model, Continuous Model

\section{INTRODUCTION}

Solar energy is essential for the functioning of all activities be it a developed or developing nation (Suganthi and Samuelb, 2012). A designing energy system has to know the solar radiation data such as: solarcollector, drying or photovoltaic and data of solar illuminance for building design or energy conversion combine with artificial lighting. In the rural aria measuring can't cover all location because of instruments is an expensive.

A solar radiation and luminance on horizontal model proposed in many research years ago. Many researches presented method of model and analysis of appropriate parameters for modeling. Typically used data from recorded at different measuring stations with standard measurement tools. Sometimes might use information derived from satellite imagery, they can do the same. For modeling, the use of the information recorded in the past for model synthetic.

Linear or non-linear modeling presented pass basic model. The model of Angstrom (1956) has basic for predict solar radiation, which this model can predict hourly, daily or monthly. But Angstrom model has been to development of other model.

Expert system model is widely used with nonlinear data such as: Artificial Neural Network, Fuzzy and Stochastic model. Artificial Neural Networks (ANNs) are attractive and promising strategies because of their capacity in prediction, control and Mahasarakham University, Khantaravichai, Mahasarakham 44150, Thailand 
optimization of input-output responses without a predefined mathematical model. Many successful applications of ANN were reported in solar energy resources fields. The ANN models for solar radiation estimation have been developed in different geographical and meteorological conditions. Nearly year, Benghanem et al. (2009) use ANN estimation of daily global solar radiation, Jiang (2008) present ANN-models for daily diffuse solar radiation. The result found that, ANN performed better than classical modeling methods. Butmost of the models lack the detailed knowledge of various parameters, such as the daily variation of sunshine duration, air temperature, precipitation, relative humidity and atmospheric pressure (Tymvios et al., 2005).

For Stochastic model, Morf (2011) presented two-state cloud cover model; cloud cover is the fraction of the sky that is covered by clouds. To adjust the model to the real world mean and variance of cloud cover and vertical visibility. Kaplanis and Kaplani (2010) proposed stochastic model for hourly global solar radiation for Patra, Greece. Hocaoglu (2011) proposed Hidden Markov model for prediction daily solar radiation. However, most previous research presented only model for hourly, daily or monthly but modeling for continuous prediction see a few.

In this article was to present a novel model for continuous predicting solar global radiation and solar diffuse radiation on horizontal surface. This model applied Hidden Markov Model (HMM) by use two observations are solar altitude angle and sky ratio.

\section{MATERIALS AND METHODS}

\subsection{Experimental Data}

The data for model synthesis use solar global and diffuse radiation from meteorology station, installed at Mahasarakham University (MSU), Mahasarakham, Thailand has been recording the solar irradiance, solar illuminance and weather data since September 16, 2004. The station is classified as general class which is recommended by ICI (1996) standard. The site is located at latitude $16^{\circ} 14^{\prime} \mathrm{N}$ and longitude $103^{\circ} 15^{\prime} \mathrm{E}$, this area is sometimes called the Isan region of Thailand. Some equipment at the measurement station is shown in Fig. 1 below.

The solar irradiance and illuminance measuring equipment were supplied by Eko of Japan. This station is classified in general class. Some an instrument list is shown in Table 1.

\subsection{Observation Value}

An observation values for predicting state of solar quantity will use two values are sky ratio and solar altitude angle. The detail of each value follows as:

\subsection{Sky Ratio}

The first observation value, we are call sky ratio. Typically, the sky brigthness is categorized in three sky types: clear sky, partly cloudy sky and overcast sky (Pattanasethanon et al., 2007). Table 2 shows the range of sky ratio. The indices which are used for classifying the sky types, the relationship of these indeces maybe calculate from Equation (1 and 2) for solar radiation and solar luminance, respectively.

Sky ratio has originally been defined as the proportion of the diffuse radiation (Eed) to the global radiation (Eeg) and used in the estimation of solar radiation. Other hand maybe calculated sky ratio from the diffuse luminance (Evd) to the global luminance (Evg) (Rahim et al., 2004):

Sky Ratio $(\mathrm{SR})=\frac{\text { Eed }}{\text { Eeg }}$ For radiation

Sky Ratio $(\mathrm{SR})=\frac{\text { Evd }}{\text { Evg }}$ For radiation

Theoretically, when the sky is completely overcast the values of sky ratio should be equal to1.0.

\subsection{Solar Altitude Angle}

Second observation value is solar altitude angle. The sun's position in the sky at one point on the earth at a particular time of the day. The calculated data are: Solar altitude angle and declination angle, the time of rise set and noon, the daylight with the difference from the previous and later day. It also displays graphs of the solar path Equation (3 and 4):

Local time $(\mathrm{LT})=$ Watch time $(\mathrm{WT}) \pm \Delta$

$\Delta=4\left(\mathrm{~L}_{\mathrm{st}}-\mathrm{L}_{10}\right)$

where, LT is the Local time, WT is the Watch time, $\mathrm{L}_{\mathrm{st}}$ is the Standard Longitude and $\mathrm{L}_{\mathrm{lo}}$ is the Longitude from special local. Equation of time follows from Equation (5):

EoT $=9.87 \sin (2 B)-7.53 \cos (B)-1.5 \sin (B)$ 
Table 1. Some equipment for experimental data at MSU meteorological stations

\begin{tabular}{|c|c|c|c|c|}
\hline \multirow[b]{2}{*}{ Sky quantity } & \multicolumn{4}{|l|}{ Measurement } \\
\hline & Sensitivity & Accuracy (\%) & Measuring range & Model \\
\hline Global horizontal illuminance & $0.206 \mu \mathrm{V} / \mathrm{lux}$ & 2.1 & $0-150$ klux & Eko/ML020S-0 \\
\hline Diffuse horizontal illuminance & $0.206 \mu \mathrm{V} / \mathrm{lux}$ & 2.1 & 0-150 klux & Eko/ML020S-0 \\
\hline Global horizontal irradiance & $7.03 \mathrm{mV} / \mathrm{Wm}^{-2}$ & 2.3 & $0-1.5 \mathrm{~kW} . \mathrm{m}^{-2}$ & Eko/ MS-802 \\
\hline Diffuse horizontal irradiance & $7.03 \mathrm{mV} / \mathrm{Wm}^{-2}$ & 2.3 & $0-1.5 \mathrm{~kW} . \mathrm{m}^{-2}$ & Eko/ MS-802 \\
\hline Data logger & \multicolumn{3}{|c|}{$\begin{array}{l}30 \text { channels, standard data acquisition; } \\
\text { Accuracy } 0.5 \%\end{array}$} & $\begin{array}{l}\text { Eko/MP-092 } \\
\text { Solac-v }\end{array}$ \\
\hline
\end{tabular}

Table 2. Rangof sky classification considered with sky ratio

\begin{tabular}{lc}
\hline Sky ratio $(\mathrm{SR})$ & Sky typical \\
\hline $0.0<\mathrm{SR} \leq 0.1$ & \\
$0.1<\mathrm{SR} \leq 0.2$ & Clear sky \\
$0.2<\mathrm{SR} \leq 0.3$ & \\
$0.3<\mathrm{SR} \leq 0.4$ & \\
$0.4<\mathrm{SR} \leq 0.5$ & Partly cloudy \\
$0.5<\mathrm{SR} \leq 0.6$ & \\
$0.6<\mathrm{SR} \leq 0.7$ & \\
$0.7<\mathrm{SR} \leq 0.8$ & \\
$0.8<\mathrm{SR} \leq 0.9$ & Overcast sky \\
$0.9<\mathrm{SR} \leq 1.0$ & \\
\hline
\end{tabular}

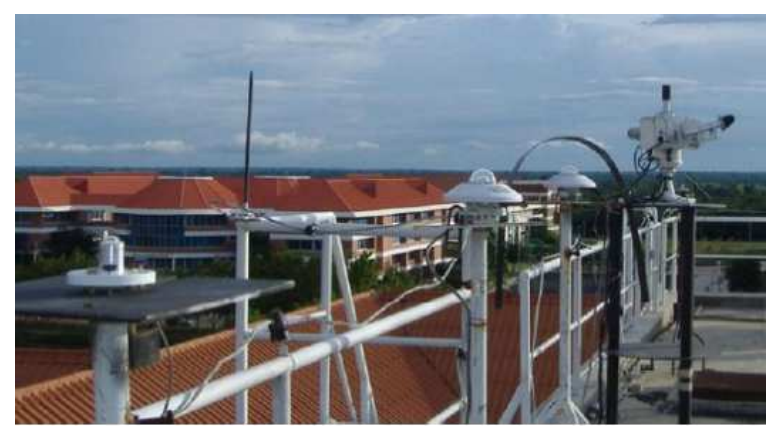

Fig. 1. Someeqiupment at the meteorology station

where, $B=(360 / 364)(n-81)$ and $n$ is the number day of the year. So that solar time can find below Equation (6):

Solar time $(\mathrm{ST})=$ Watch time $(\mathrm{WT}) \pm \Delta+$ Eot

The declination angle, may defined as the angle between the line joining the centers of the sun Equation (7):

$\mathrm{d}=23.45 \sin \left(\frac{360(284+\mathrm{n})}{365}\right)$

Solar hour angle, it is the angle through which the earth must be rotated to bring the meridian of the plane directly under the sun. It can find from Equation (8 and 9):

$$
\varpi=15(t-12)
$$

where, $\mathrm{t}$ is the solar time. Solar altitude angle, $\beta$ can find:

$$
\sin \beta=\cos \ell \cdot \cos \omega \cdot \cos d+\sin \ell \cdot \sin d
$$

\subsection{Hidden Markov Model}

The Hidden Markov Model (HMM) was a statistical model used for classifying kinds of signals by using the statistical process to create a model. This model has been improved over several years from the Markov Models, which was created by a Russian Mathematician Andrei Andreevich Markov.

Later in 1960 to 1970 , Baum and his team members divulged their research about Hidden Markov Model (Rabiner, 1989). Several researches even used the Hidden Markov Model to predict the weather (Jones and Thornton, 1999). In this article, the Hidden Markov Model, Ergodic model (fully connected) type show in Fig. 2, was used to predict the solar radiation

\subsection{Basic Architecture}

The composition of the Hidden Markov Model was determined by three parametric values which consist of.

First, matrix A is a state transition probability array, storing the probability of state $S_{j}$ following state $S_{i}$. Note the state transition probabilities are independent of time Equation (10):

$$
A=\left[a_{i j}\right]=\left[\begin{array}{ccccc}
a_{11} & a_{12} & a_{13} & \cdots & a_{1 n} \\
a_{21} & a_{22} & a_{23} & \cdots & a_{2 n} \\
a_{31} & a_{32} & a_{33} & \cdots & a_{3 n} \\
\vdots & \vdots & \ddots & & \vdots \\
a_{n 1} & a_{n 2} & a_{n 3} & \cdots & a_{n n}
\end{array}\right]
$$

where, $a_{i j}=P\left[q_{t}=S_{j} \mid \quad q_{t-1}=S_{i}\right], \quad 1 \leq \mathrm{i}, \quad j \leq N, \quad S$ denote individual state where $\mathrm{S}=\left[\mathrm{S}_{1}, \mathrm{~S}_{2}, \mathrm{~S}_{3}, \ldots, \mathrm{S}_{\mathrm{N}}\right], \mathrm{N}$ is number of state in model, $\mathrm{a}_{\mathrm{ij}}$ is the time independent probability of having state $S_{j}$ at $t+1$ given that the state at time $t$ was S. $q$ is the state sequence and notice value $\sum_{j=1}^{n} a_{i j}$ of must to equal 1 . 


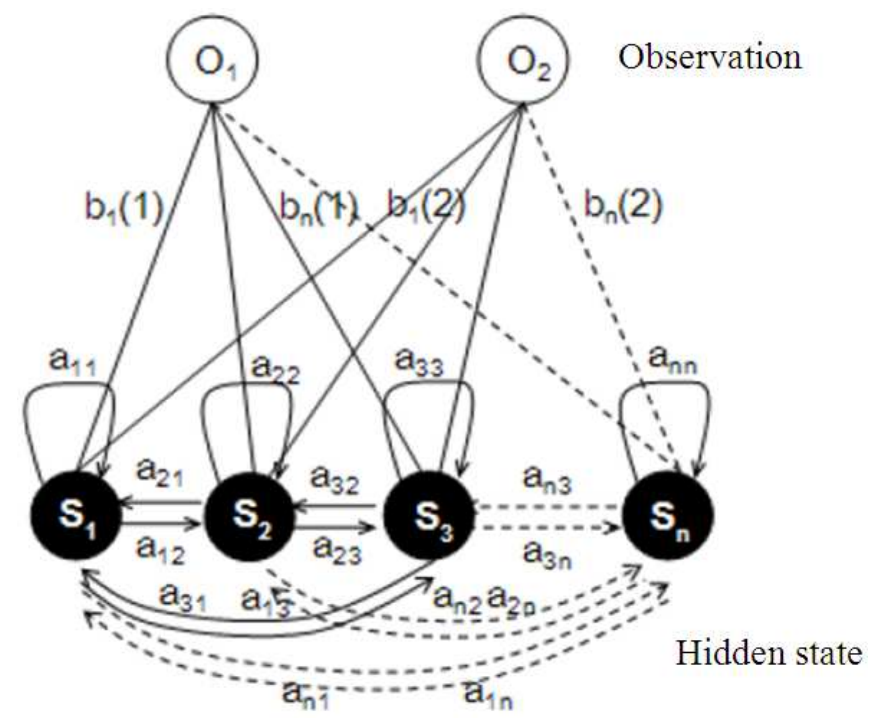

Fig. 2. Hidden Markov model architecture, $\mathrm{Si}$ is the seqence of solar irradiance, $\mathrm{O}$ are observation symbols (O1is the solar altitude angle and $\mathrm{O} 2$ is the sky ratio $\mathrm{n}$ )

Second, matrix B is the observation array, storing the probability of observation $\mathrm{k}$ being produced from the state $\mathrm{j}$, independent of $\mathrm{t}$ defined by Equation (11):

$\mathrm{B}=\left[\mathrm{b}_{1 \mathrm{k}}, \mathrm{b}_{2 \mathrm{k}}, \mathrm{b}_{3 \mathrm{k}} \ldots \mathrm{b}_{\mathrm{Nk}}\right]$

where, $b_{j}(k)=P\left[v_{k}\right.$ at $\left.t \mid q_{t}=S_{j}\right], 1 \leq j \leq N, 1 \leq k \leq M, M$ is the number of distinct observation symbols per state.

The last, matrix $\Pi$ is the initial probability array defined by Equation (12):

$$
\prod=\left[\prod_{\mathrm{i}}\right]_{\text {where }} \prod_{\mathrm{i}}=\mathrm{P}\left[\mathrm{q}_{\mathrm{l}}=\mathrm{S}_{\mathrm{i}}\right], 1 \leq \mathrm{i} \leq \mathrm{N}
$$

To summarize previous calculations, the equation $\lambda$ $=(\mathrm{A}, \mathrm{B}, \Pi)$ was used to indicate the complete parameter set of the Hidden Markov model.

\subsection{The Concept Model}

The data recorded from meteorology station has averaged every $5 \mathrm{~min}$, after that an arrangement data in time seqence. Figure 3 shows some example of $\mathrm{Si}$ is the time seqence of global solar radiation from $t=1$ to $t$ $=5,000$ The HMM has been classification of data by use to clustering of global solar radiation and diffuse radiation. The global solar radiation have a significant number of groups are 40 groups. The level of global solar radiation between clustering equal $25 \mathrm{~W} / \mathrm{m}^{2}$, interval of data set as $0-1000 \mathrm{~W} / \mathrm{m}^{2}$.
In the same way, for diffuse solar radiation set data min-max equal $0-400 \mathrm{~W} / \mathrm{m}^{2}$, the level of diffuse solar radiation between clustering equal $10 \mathrm{~W} / \mathrm{m}^{2}$, for 40 groups. The concept for HMM synthetic show as Fig. 4 below.

\subsection{Training Model}

Training the model. We would validate for the parametric value $\mathrm{A}, \mathrm{B}$ and $\Pi$ by determining the measured solar radiation in time sequence. The parametric value estimation of $\mathrm{A}, \mathrm{B}$ and $\Pi$ of Hidden Markov model used Baum-Welch Algorithm below.

Parametric value estimation $a_{i j} b_{j}(k)$ and of BaumWelch Algorithm for A, B and $\prod$ are $\mathrm{a}_{\mathrm{ij}}=\mathrm{P}\left[\mathrm{q}_{\mathrm{t}}=\mathrm{S}_{\mathrm{j}} \mid \mathrm{q}_{\mathrm{t}-1}=\right.$ $\left.\mathrm{S}_{\mathrm{i}}\right], 1 \leq \mathrm{i}, \mathrm{j} \leq \mathrm{N}$ Equation (13):

$\mathrm{a}_{\mathrm{ij}}=\frac{\sum_{\mathrm{t}=1}^{\mathrm{T}-1} \xi(\mathrm{i}, \mathrm{j})}{\sum_{\mathrm{t}=1}^{\mathrm{T}-1} \gamma_{\mathrm{t}}(\mathrm{i})}$

where, $\sum_{t=1}^{\mathrm{T}-1} \xi(\mathrm{i}, \mathrm{j})$ is the expected number of transitions from state $S_{i}$ to state $S_{j}$ at any time in the data sequence. $\sum_{t=1}^{\mathrm{T}-1} \gamma_{t}(\mathrm{i})$ is the expected number of transition from state Siat step t. $b_{j}(k)=P\left[v_{k}\right.$ at $\left.t \mid q_{t}=S_{j}\right], 1 \leq j \leq N, 1$ $\leq \mathrm{k} \leq \mathrm{M}$ Equation (14):

$b_{j}(k)=\frac{\sum_{t=1, o_{t}=v_{k}}^{T} \gamma_{t}(j)}{\sum_{t=1}^{T} \gamma_{t}(j)}$ 


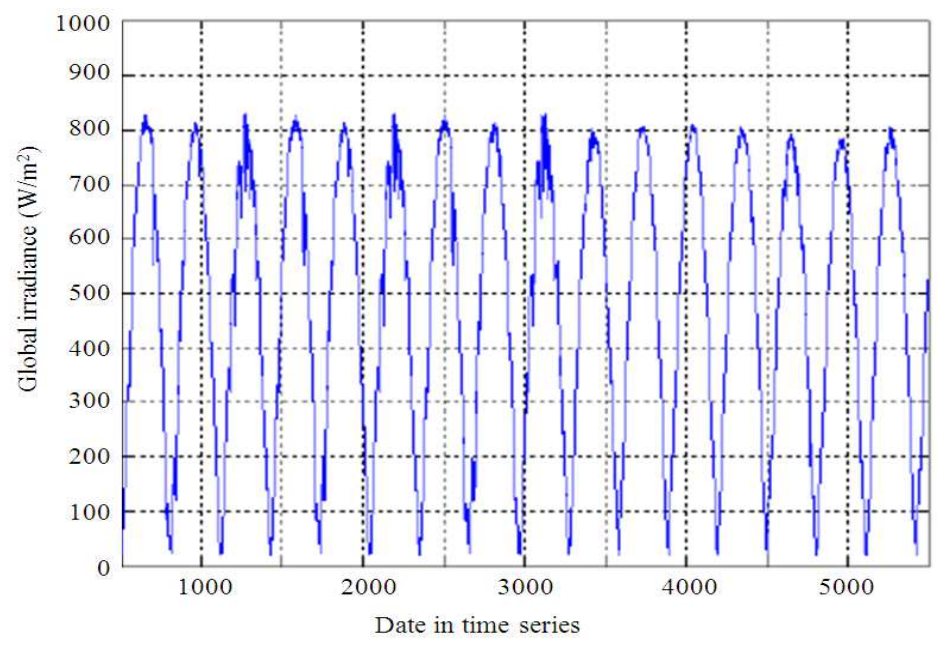

Fig. 3. Theexample 1 to 5,000 point for data in time series

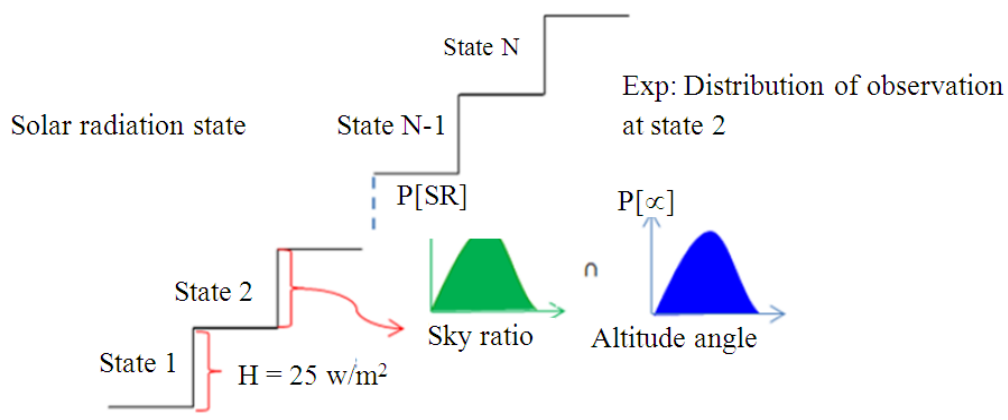

Fig. 4. Concept of model, show example at state 2, all data each probability of observation value

where, $\sum_{t=1,0_{t}=v_{k}}^{T} \gamma_{t}(j)$ is the expected number of time in state $\mathrm{j}$ observing $\mathrm{v}_{\mathrm{k}}$ and $\sum_{\mathrm{t}=1}^{\mathrm{T}} \gamma_{\mathrm{t}}(\mathrm{j})$ is the expected number of time in state $\mathrm{j}$ Equation (15):

$$
\prod_{\mathrm{i}}=\gamma_{1}(\mathrm{i})
$$

where, (i) $\gamma_{1}$ the expected number of time in state $i$ at time 1. Transition Matrix A appears like Homogeneous Matrix, when Transition Matrix was graphed, the relation of the state differences at the time $t$ to state $S_{j}$ at the time $\mathrm{t}+1$ as Fig. 5.

The information based on the observations from matrix A would be distributed to compare the observation value to create a probability matrix of the observatoion in every set of state. Therefore, information would have to be distributed in sets of different information from state $i$ to state $j$. Figure 6 was the example of observation distribution on sky ratio and solar altitude angle. In Fig. 6a, if the sky ratio was known, the probability in the event would be known too. In Fig. 6b, the same characteristic was shown, which if solar altitude angle was known the probability would be known too, if the observation value is stable. The process of distributing the observation value would be present in every states.

\subsection{Predicting}

The practice of the Hidden Markov model solves for the probability of state that the observation value was known by using a forward algorithm with every sub model (each state). The sub model which gives the highest probability is considered the observation value. The sate value can be calculated if the observation value is known as the solar altitude angle and sky ratio. 
Somporn Hongkong and Singthong Pattanasethanon / American Journal of Environmental Science 9 (3): 201-209, 2013

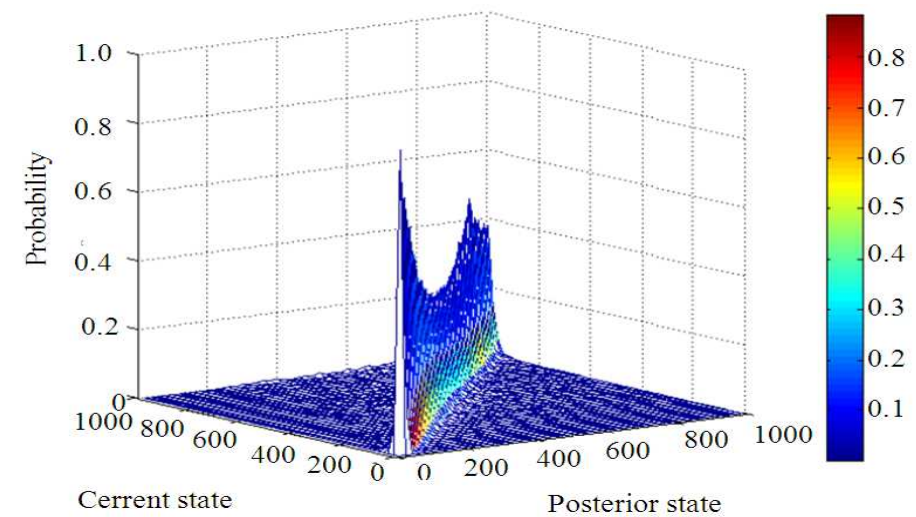

Fig. 5. Probability of the difference state from i to $j$, the total radiation value of Hidden Markov Model

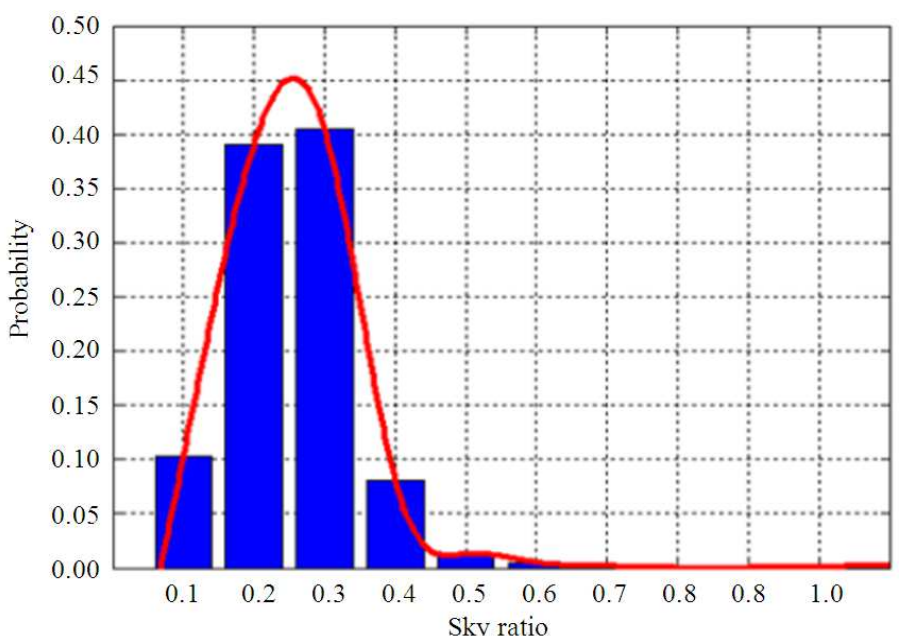

(a)

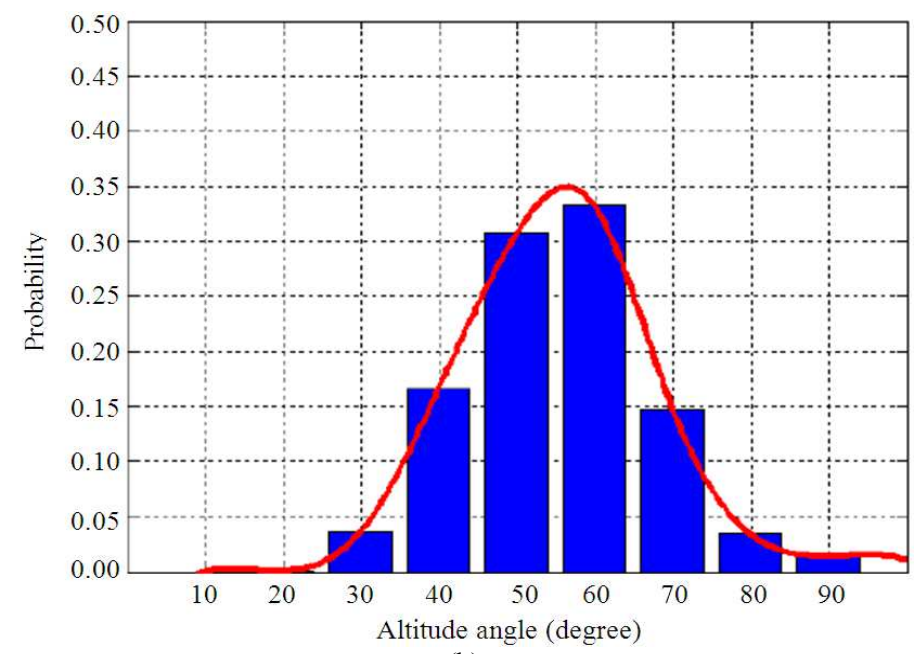

(b)

Fig. 6. Theexample for data distribution in state i of observation value 
Choosing the state with the highest probability, which was hidden in the model. When the observation value was known, use Equation 16 to choose the state with highest probability:

$$
\begin{aligned}
& \mathrm{S}^{*}=\arg \max \mathrm{P}(\text { Observation } \mid \mathrm{HMM}) \\
& \mathrm{S}=\left(\mathrm{S}_{1} \ldots \mathrm{S}_{\mathrm{T}}\right)
\end{aligned}
$$

where, Observation is probability of observation matric calculated from $\mathrm{P}[\mathrm{SR} \cap \alpha], \mathrm{S} *$ is the hight probability state in observation at any time and scalling to solar radiation by number of cluser cross rang of.

\subsection{Model Evaluation}

Three statistics, Mean Bias Deviation (MBD), Root Mean Square Deviation (RMSD) and Coefficients of Determination $\left(\mathrm{R}^{2}\right)$, were used as evaluation criteria in this study and the relationship of those equations are expressed as Equation 17-19, respectively:

$$
\begin{aligned}
& \text { MBD }=\frac{\sum_{\mathrm{i}=1}^{\mathrm{n}}\left(\mathrm{E}_{\text {model }, \mathrm{i}}-\mathrm{E}_{\text {meas }, \mathrm{i}}\right)}{\mathrm{n} \cdot \mathrm{E}_{\text {mean }}} \\
& \mathrm{RMSD}=\left(\frac{1}{\mathrm{E}_{\text {mean }}}\right) \cdot \sqrt{\frac{\sum_{\mathrm{i}=1}^{\mathrm{n}}\left(\mathrm{E}_{\text {model }}-\mathrm{E}_{\text {mean }}\right)^{2}}{\mathrm{n}}} \\
& \mathrm{R}^{2}=\frac{\sum_{\mathrm{i}-1}^{\mathrm{n}}\left(\mathrm{E}_{\text {model }}-\mathrm{E}_{\text {meas }}\right)^{2}}{\sum_{\mathrm{i}-1}^{\mathrm{n}}\left(\mathrm{E}_{\text {meas }}-\mathrm{E}_{\text {meam }}\right)^{2}}
\end{aligned}
$$

where, $\mathrm{E}_{\text {meas }}$ and $\mathrm{E}_{\text {model }}$ is the measured and calculated data, respectively. $\mathrm{E}_{\text {mean }}$ is mean of data from measured. $\mathrm{n}$ is number of records of data in the testing set. MBD shows the model tendency and RMSD describes the short term error and $\mathrm{R}^{2}$ is show the relation between data from measured and calculated.

\section{RESULTS AND DISCUSSION}

\subsection{Results}

Figure 7 plotting the HMM-predicted values of solar radiation for Figure $\mathbf{7 a}$ is global solar radiation found that the data from predicted with HMM appropriation for prediction. Figure $\mathbf{7 b}$ is diffuse solar radiation found that, the some data point maybe error from measured but mostly still following true data.

Figure $\mathbf{8}$ is compared between measured and calculated of global and diffuse solar radiation data. For statistics analysis show in Table 2.

\subsection{Discussion}

The performance of the models is estimated on the basis of the following statistical error tests: Mean Bias Determination (MBD) is, Root Mean Square Determination (RMSD) and coefficients of determination $\left(\mathrm{R}^{2}\right)$ can be calculated follow Equation 16 to 18 . These tests are the ones that are applied most commonly in comparing the models of solar radiation estimations.

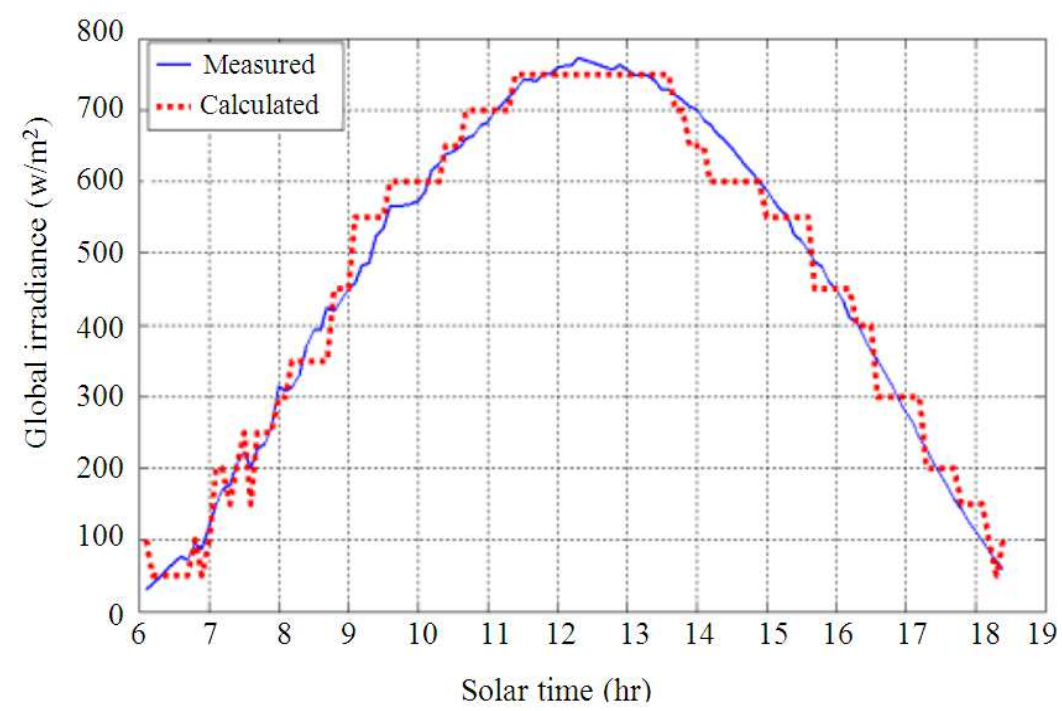

(a) 
Somporn Hongkong and Singthong Pattanasethanon / American Journal of Environmental Science 9 (3): 201-209, 2013

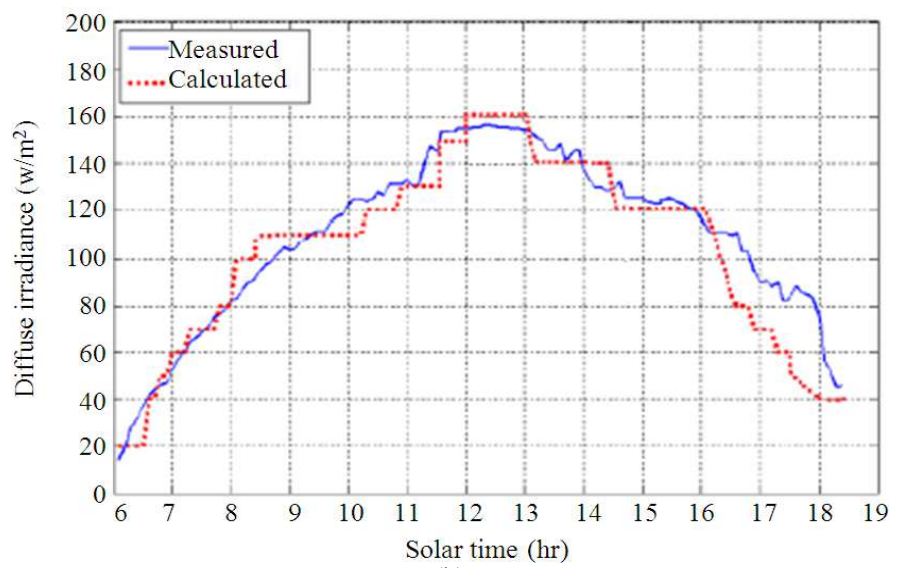

(b)

Fig. 7. Plotting between measured and calculated of global and diffuse irradiance

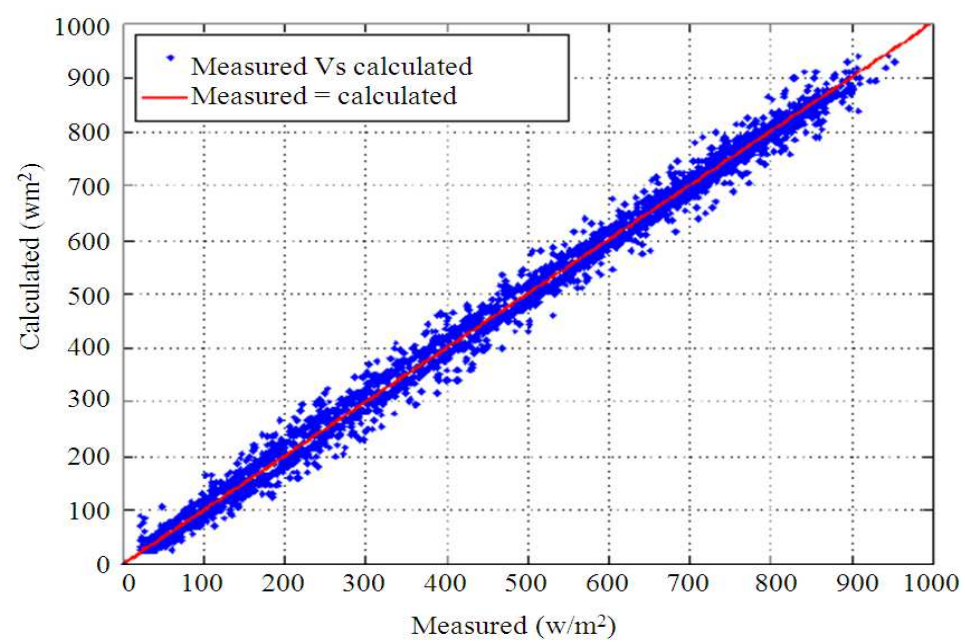

(a)

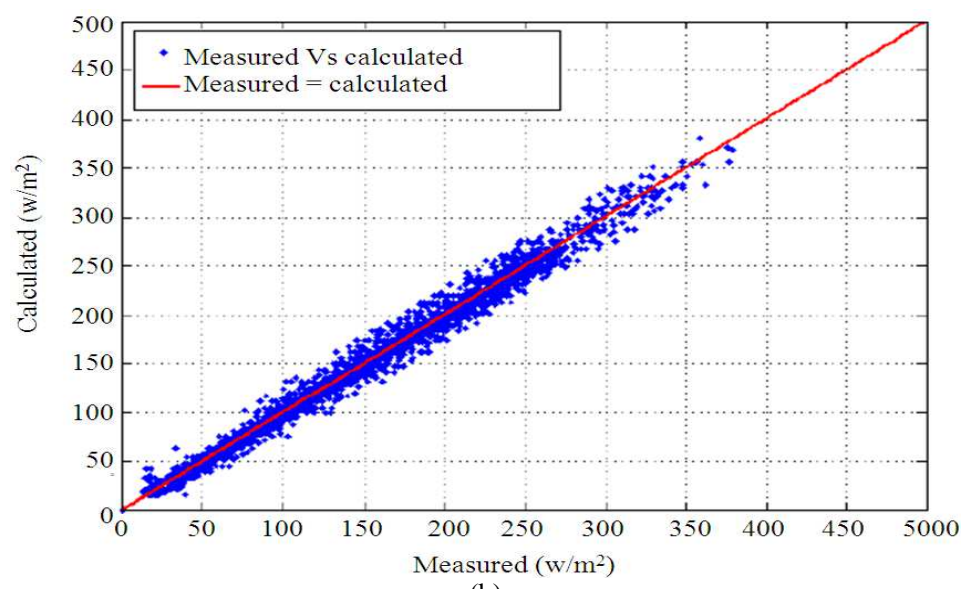

(b)

Fig. 8. Measured versus calculated of sky ratio classification 


\section{CONCLUSION}

In this study, a novel approach for solar global and diffuse irradiance modeling base on sky ratio and solar altitude angle are presented. The advantages of the model can be summarized as below:

- Unlike previous models as can predicted only daily, hourly solar global radiation but this model can be calculate at every the time on sunshine

- High accuracy in prediction, because of this model has been development from long-term data and predicted by using optimization technique

- Domain of model consists of sky ratio and solar altitude angle are called observation value, sky ratio maybe detect by lux-meter for measure global and diffuse illuminance. Solar altitude angle calculated from the location at time of the day

- The model is open for improvement. Several other combinations of geographical data such as: air temperature, air pressure and humidity

\section{ACKNOWLEDGMENT}

The reachers would like to express their sincere thanks to the Solar Energy and Power Electronics Research Unit, Faculty of Engineering of Mahasarakham University for the data support.

\section{REFERANCES}

Angstrom, A., 1956. On the computation of global radiation from records of sunshine. Arkiv Geof, 2: 471-479.

Benghanem, M., A. Mellit and S.N. Alamri, 2009. ANNbased modelling and estimation of daily global solar radiation data: A case study. Energy Conver. Manage., 50: 1644-1655. DOI: 10.1016/j.enconman.2009.03.035

Hocaoglu, F.O., 2011. Stochastic approach for daily solar radiation modeling. Solar Energy, 85: 278-287. DOI: 10.1016/j.solener.2010.12.003
ICI, 1996. Spatial Distribution of Daylight-CIE Standards Overcast Sky and Clear Sky. 1st Edn., International Commission on Illumination, Vienna, pp: 05.

Jiang, Y., 2008. Prediction of monthly mean daily diffuse solar radiation using artificial neural networks and comparison with other empirical models. Energy Policy, 36: 3833-3837. DOI: 10.1016/j.enpol.2008.06.030

Jones, P.G. and P.K. Thornton, 1999. Fitting a thirdorder Markov rainfall model to interpolated climate surfaces. Agric. Forest Meteorol., 97: 213-231. DOI: 10.1016/S0168-1923(99)00067-2

Kaplanis, S. and E. Kaplani, 2010. Stochastic prediction of hourly global solar radiation for Patra, Greece. Applied Energy, 87: 3748-3758. DOI: 10.1016/j.apenergy.2010.06.006

Morf, H., 2011. The stochastic two-state cloud cover model stsccm. Solar Energy, 85: 985-999. DOI: 10.1016/j.solener.2011.02.015

Pattanasethanon, S., C. Lertsatitthana-Korn, S. Atthajariyakul and S. Soponronnarit, 2007. All sky modeling daylight availability and illuminance/irradiance on horizontal plane for Mahasarakham, Thailand. Energy Conver. Manage., 48: 1601-1614. DOI: 10.1016/j.enconman.2006.11.012

Rahim, R., Baharuddin and R. Mulyadi, 2004. Classification of daylight and radiation data into three sky conditions by cloud ratio and sunshine duration. Energy Build., 36: 660-666. DOI: 10.1016/j.enbuild.2004.01.012

Rabiner, L., 1989. A tutorial on hidden markov models and selected applications in speech recognition. IEEE Proc., 77: 257-285. DOI: 10.1109/5.18626

Suganthi, L. and A.A. Samuelb, 2012. Energy models for demand forecasting-A review. Renewable Sustainable Energy Rev., 16: 1223-1240. DOI: 10.1016/j.rser.2011.08.014

Tymvios, F.S., C.P. Jacovides, S.C. Michaelides and C. Scoutelic, 2005. Comparative study of Angstrom's and artificial neural networks' methodologies in estimating global solar radiation. Solar Energy, 78: 752-762. DOI: 10.1016/j.solener.2004.09.007 